\title{
Reduced dose salbutamol in comparison with standard dosage for symptom relief in asthma
}

\author{
D.H. Yates, M.J. Peters, V. Keatings, P.S. Thomas, P.J. Barnes
}

\begin{abstract}
Reduced dose salbutamol in comparison with standard dosage for symptom relief in asthma. D.H. Yates, M.J. Peters, V. Keatings, P.S. Thomas, P.J. Barnes. CERS Journals Ltd 1995.

ABSTRACT: Regular treatment with $\beta_{2}$-agonists has been reported to be associated with an increase in risk of asthma death or near death, and with a deterioration in asthma symptom control. Low-dose $\beta_{2}$-agonists provide effective bronchodilatation and bronchoprotection, even though maximal bronchodilatation is not achieved, and they may offer a better safety profile.

In a double-blind, randomized, cross-over study, we evaluated the efficacy of lowdose salbutamol metered-dose inhaler $\left(50 \mu \mathrm{g}^{\cdot}\right.$ puff- $\left.^{-1}\right)$, used over a period of 2 weeks, compared with a standard dose $\left(100 \mu \mathrm{g} \cdot\right.$ puff $\left.^{-1}\right)$ in control of asthma symptoms in 20 moderately severe asthmatic subjects using inhaled glucocorticosteroid therapy. Asthma control was assessed by symptom scores, peak flow rates, spirometry, inhaler usage and, where possible, by bronchial responsiveness to methacholine.

Despite a $46 \%$ reduction in mean weekly salbutamol dosage, mean forced expiratory volume in one second (FEV1), morning and evening peak expiratory flow (PEF), PEF variability, dose of methacholine provoking a $20 \%$ decrease in FEV1 $(\mathbf{P C 2 0})(n=9)$, and symptom scores showed no difference between low-dose and standard inhaler treatment periods. Low-dose inhaler administration resulted in a small but significant increase in number of inhaler actuations.

Low-dose salbutamol metered-dose inhaler may, thus, be useful for control of symptoms in moderately severe asthma. This strategy could be used to achieve a reduction in total $\beta_{2}$-agonist usage, which may minimize any potential for adverse effects. Eur Respir J., 1995, 8, 1847-1851.
\end{abstract}

\author{
Dept of Thoracic Medicine, National \\ Heart \& Lung Institute, London, UK. \\ Correspondence: D.H. Yates \\ Concord Hospital \\ Sydney \\ NSW 2139 \\ Australia \\ Keywords: $\beta_{2}$-agonist tolerance \\ dose reduction \\ salbutamol
}

Received: May 31995

Accepted after revision August 161995 $\beta_{2}$-adrenoceptor agonists provide highly effective relief for acute asthma symptoms and are the most widely prescribed drug for asthma in industrialized countries [1]. However, recent studies have suggested that overuse of $\beta_{2}$-agonists may worsen asthma control [2, 3], and may be associated with increased morbidity and mortality in asthma [4]. Any adverse effects of $\beta_{2}$-agonists may depend on the dose of the drug used. The epidemic of asthma deaths observed in the 1960s was temporally associated with the introduction of a high-dose isoprenaline formulation [5], and subsided after this was withdrawn [6]. A more recent epidemic of asthma deaths in New Zealand has been associated with the use of fenoterol, which was marketed in a relatively high dosage [7]. The results of one recent epidemiological study suggest a dose-response relationship between risk of asthma death and the dosage of inhaled $\beta_{2}$-agonist prescribed [4].

Shortly after inhaled $\beta_{2}$-agonists were first introduced, individual cases were reported in which deleterious effects of $\beta_{2}$-agonists used in high-dose were documented [8], with improvement in asthma control following $\beta_{2}$-agonist withdrawal [9]. When the newer selective $\beta_{2}$-agonists, such as terbutaline and salbutamol, were introduced, they were marketed at a dose originally determined by comparison with isoprenaline $1,000 \mu \mathrm{g}$ [10], a dose which may have been too high $[6,11]$. The dose of the shorteracting $\beta_{2}$-agonists has, nonetheless, remained unchanged, and $\beta_{2}$-agonists are prescribed as a standard dose, without adjustment for body size. Salbutamol, although marketed in $100 \mu \mathrm{g} \cdot$ actuation $^{-1}$, will produce effective bronchodilatation at less than $25 \mu \mathrm{g}$ [12-15]. Low-dose formulations could potentially produce equivalent bronchodilatation in asthma whilst providing a better safety profile. If asthma control indeed deteriorates on high-dose $\beta_{2}$-agonists, a reduction in dose might improve asthma symptoms.

In order to study this question, we examined the efficacy of a low-dose formulation of salbutamol $\left(50 \mu \mathrm{g} \cdot\right.$ puff $\left.^{-1}\right)$, used when needed for relief of asthma symptoms, in a group of moderately severe asthmatic subjects, all requiring moderately high doses of inhaled glucocorticosteroids for optimal symptom control.

\section{Methods}

\section{Subjects}

Twenty four nonsmoking asthmatic subjects meeting the American Thoracic Society diagnostic criteria for asthma [16] (13 male and 11 females, mean age $49 \pm 3$ yrs) 
(table 1) were recruited. All subjects had $>15 \%$ reversibility to $200 \mu \mathrm{g}$ salbutamol, and/or peak expiratory flow (PEF) variability of $>15 \%$, and moderately severe or severe asthma. All had previously used either higher dose inhaled or oral glucocorticosteroid therapy, and their asthma control had been stabilized in the out-patient clinic on the dose of inhaled glucocorticosteroid used in the study. All gave written informed consent to participate in the study, which was approved by the Royal Brompton Hospital Ethics Committee. All subjects had daily symptoms of variable wheeze and dyspnoea, and all were using inhaled glucocorticosteroids. Subjects were selected for the study only if they used more than four puffs of salbutamol daily. Three patients also used salmeterol and four used aminophylline. All medications other than salbutamol were maintained at stable dosage throughout the study, and all patients used salbutamol on an as-needed basis during the study period. Atopy was defined by one or more of the following: skin-prick tests to six common aeroallergens $>2 \mathrm{~mm}$ greater than control; history of atopy (seasonal rhinitis, eczema); or elevated immunoglobin E (IgE) [17].

No subject had suffered an asthma exacerbation or respiratory tract infection within the 6 weeks preceding the study, nor used oral glucocorticosteroids less than 12 weeks before study entry. Inhaled bronchodilators and caffeine-containing drinks were withheld for at least $12 \mathrm{~h}$ ( $24 \mathrm{~h}$ for salmeterol) before each study visit, and theophyllines for $24 \mathrm{~h}$. Patients attended the laboratory at approximately the same time of day. Study inhalers were weighed before and after each treatment period in order to allow an assessment of compliance.

\section{Study design}

The study was double-blind, randomized and crossover. After a screening visit, patients entered a run-in period of 2 weeks, during which the patient remained on her/his usual medication. Patients were then randomly allocated either to reduced dose or standard dose metereddose inhaler (MDI) for 2 weeks, and the alternative study treatment was then used for a further 2 weeks. Salbutamol, 100 and $50 \mu \mathrm{g} \cdot$ puff $^{-1}$ were kindly supplied by $3 \mathrm{M}$ Australia. Asthma control was measured by serial peak flows, symptom scores, rescue inhaler usage, spirometry, and provocative concentration of methacholine causing a $20 \%$ reduction in forced expiratory volume in one second (FEV1), (PC20) where FEV1, was $>65 \%$.

Symptom scores were measured on a $0-3$ scale for early morning tightness, asthma last night and asthma during the day. Daily inhaler usage was also recorded. Scores were as follows: early morning tightness: $0=$ none; $1=$ mild tightness, no effect on routine activity; $2=$ moderate tightness affecting routine activity; $3=$ severe tightness. Asthma last night: $0=$ none; $1=$ woken once; $2=$ woken $2-4$ times; $3=$ awake most of the night due to asthma. Asthma during the day: $0=$ none; $1=$ mild wheeze, no effect on daily activity; 2=moderate wheeze affecting routine activity; $3=$ unable to perform normal daily activity.

\section{Bronchial provocation challenge}

Bronchial provocation challenge was performed according to our standardized technique [18]. Fresh solutions of methacholine (MCh) (Sigma, Poole, UK) were made

Table 1. - Patient characteristics

\begin{tabular}{|c|c|c|c|c|c|c|c|c|}
\hline $\begin{array}{l}\mathrm{Pt} \\
\text { No. }\end{array}$ & $\begin{array}{l}\text { Age } \\
\text { yrs }\end{array}$ & Sex & $\begin{array}{l}\text { FEV1 } \\
\% \text { pred }\end{array}$ & Atopy & $\begin{array}{c}\operatorname{IgE} \\
\mathrm{U} \cdot \mathrm{L}^{-1}\end{array}$ & $\begin{array}{c}\text { Eos } \\
\times 10^{9} \cdot \mathrm{L}^{-1} \\
\end{array}$ & $\begin{array}{c}\text { Total GCS } \\
\text { therapy }\end{array}$ & Other medication \\
\hline 1 & 47 & $\mathrm{~F}$ & 89 & + & 160 & 0.4 & Bud $800 \mu \mathrm{g}$ b.d.. & - \\
\hline 2 & 43 & $\mathrm{M}^{\#}$ & 84 & + & 266 & 0.4 & Bud $800 \mu \mathrm{g}$ b.d.. & - \\
\hline 3 & 30 & M & 94 & + & 60 & 0.2 & Bud $800 \mu \mathrm{g} b . d .$. & - \\
\hline 4 & 39 & M & 75 & + & 61 & 0.3 & Bud $1.6 \mathrm{mg}$ b.d. & - \\
\hline 5 & 33 & $\mathrm{M}^{\#}$ & 104 & + & 247 & 0.3 & BDP $1000 \mu \mathrm{g} b . d$. & - \\
\hline 6 & 52 & $\mathrm{~F}$ & 63 & + & 22 & 0 & Bud $800 \mu \mathrm{g} b . d$. & - \\
\hline 7 & 25 & M & 72 & + & 196 & 0.2 & Bud $800 \mu \mathrm{g}$ b.d. & - \\
\hline 8 & 40 & $\mathrm{~F}$ & 49 & + & 41 & 0.2 & Bud $1.2 \mathrm{mg}$ b.d. & - \\
\hline 9 & 52 & M & 54 & + & 37 & 0.5 & Bud $1.6 \mathrm{mg}$ b.d. & - \\
\hline 10 & 66 & M & 56 & + & 58 & 0.2 & BDP $400 \mu \mathrm{g} b . d$. & - \\
\hline 11 & 40 & M & 49 & + & 772 & 0.4 & Bud $800 \mu \mathrm{g}$ b.d. & Salmeterol $50 \mu \mathrm{g}$ b.d. \\
\hline 12 & 71 & $\mathrm{M}^{\#}$ & 32 & + & 249 & 0.5 & $\begin{array}{l}\text { BDP } 1.5 \mathrm{mg} \text { a.m., } \\
500 \mu \mathrm{g} \text { p.m. }\end{array}$ & - \\
\hline 13 & 63 & M & 24 & + & 27 & 0 & BDP $1.5 \mathrm{mg} b . d$. & - \\
\hline 14 & 55 & $\mathrm{~F}$ & 66 & - & 54 & 0.3 & BDP $1.5 \mathrm{mg} \mathrm{b.d.}$ & - \\
\hline $15 *$ & 60 & M & 51 & + & 59 & 0.5 & BDP $1.5 \mathrm{mg}$ q.i.d. & Theo $300 \mathrm{mg}$ b.d. \\
\hline $16 *$ & 36 & $\mathrm{~F}$ & 59 & + & 1544 & 0.2 & BDP $1 \mathrm{mg} b . d$. & Theo $225 \mathrm{mg}$ b.d. \\
\hline 17 & 40 & $\mathrm{M}^{\#}$ & 70 & + & 140 & 0.7 & Bud $1.6 \mathrm{mg}$ b.d. & - \\
\hline 18 & 83 & $\mathrm{~F}^{\#}$ & 63 & - & 249 & 0.5 & Bud $400 \mu \mathrm{g}$ b.d. & Nifedipine $10 \mathrm{mg} \mathrm{b.d}$. \\
\hline 19 & 38 & M & 39 & + & 31 & 0.1 & BDP $400 \mu \mathrm{g} b . d$. & Theo 300 mg p.m. \\
\hline 20 & 36 & $\mathrm{~F}$ & 66 & + & ND & 1.1 & Bud $1.6 \mathrm{mg}$ & Oxivent 2 puffs $b . d$. \\
\hline $21 *$ & 51 & $\mathrm{M}^{\#}$ & 34 & + & 49 & 0.3 & Flut $500 \mu \mathrm{g}$ b.d. & Salmeterol $50 \mu \mathrm{g}$ b.d. \\
\hline 22 & 60 & $\mathrm{~F}^{\#}$ & 66 & + & 68 & 0.1 & BDP $400 \mu \mathrm{g} b . d$. & Salmeterol $50 \mu \mathrm{g}$ b.d. \\
\hline 23 & 38 & M & 57 & + & 1385 & 0.1 & Flut $500 \mu \mathrm{g} b . d$. & Ipratropium p.r.n. \\
\hline $24 *$ & 50 & $\mathrm{~F}$ & 72 & + & 14 & 0.1 & Bud $800 \mu \mathrm{g} b . d$. & Theo $225 \mathrm{mg} \mathrm{b.d}$. \\
\hline
\end{tabular}

FEV1: forced expiratory volume in one second; Eos: peripheral blood eosinophil count; IgE: immunoglobulin E; +: atopic; -: nonatopic; Bud: budesonide; BDP: beclomethasone dipropionate; Flut: fluticasone; Theo: theophylline; GCS: glucocorticosteroid; Pt: patient; M: male; F: female. *: withdrew from study; \#: ex-smoker. ND: not done. Normal range for eosinophils $0-0.4 \times 10^{9}$ cells $\cdot \mathrm{L}^{-1}$. Normal range for $\operatorname{IgE} 25-150 \mathrm{U} \cdot \mathrm{L}^{-1}$. 
up in $0.9 \%$ saline in doubling dilutions $\left(0.06-32 \mathrm{mg} \cdot \mathrm{mL}^{-1}\right)$. Each solution was administered from a nebulizer attached to a breath-activated dosimeter (Mefar, Brescia, Italy). The nebulizer delivered particles with an aerodynamic mass median diameter of $3.5-4 \mu \mathrm{m}$ at an output of 9 $\mu \mathrm{L} \cdot$ breath $^{-1}$

After resting quietly, baseline spirometry was assessed by three forced expiratory manoeuvres using a dry wedge spirometer (Vitalograph, Buckingham, UK). Subjects then inhaled five breaths of saline and FEV1 was measured 2 min after the last inhalation. Incremental doses of MCh were administered at 3 min intervals. Challenges were terminated when a $20 \%$ decrease in FEV1 from the post saline value was reached.

\section{Statistical methods}

FEV1, and PEF data were analysed by analysis of variance (ANOVA) and paired two-tailed t-tests. Values are expressed at mean \pm standard error (SEM), unless otherwise specified. Symptom scores were analysed by Friedman's test for nonparametric data, as these are not normally distributed. PC20 values were $\log _{10}$ transformed for analysis. These were compared by ANOVA and paired two tailed t-tests. Geometric mean concentrations were calculated by taking the antilog of the mean PC20 values and expressed in the text as $\mathrm{mg} \cdot \mathrm{mL}^{-1}$ with SEM. Significance was taken as a p-value of less than 0.05. Based on the standard deviation of the difference in FEV1, observed during an initial assessment using the same symptom score and airway measurements in clinic patients, and an estimated clinically relevant difference in FEV1 of $300 \mathrm{~mL}$, we aimed to complete the study in 20 patients, to achieve a power of 0.80 . The proportion of subjects showing better control with one or other treatment regimen as assessed by graded outcome variables was not used to assess treatment effect (although this has been used previously [2]), as this had not been our original plan and the number of subjects in our study was insufficient to provide useful results.

\section{Results}

\section{Patients}

Twenty four patients were recruited, of whom 20 completed the study (table 1). Four subjects withdrew in the run-in period, two because of asthma exacerbations that necessitated oral prednisolone treatment, and two because of domestic and work commitments. Results from these patients were excluded from analysis. Ten patients were initially treated with the low-dose salbutamol inhaler, and 10 with the standard dose. All patients were nonsmokers, although six had smoked (maximum 15 pack-years) more than one year before study entry; none of these had regular sputum production or irreversible airway obstruction suggestive of chronic airflow obstruction.

\section{FEVI and PEF}

The mean FEV1, at the end of each treatment period was identical (2.33 versus $2.32 \mathrm{~L}$ ) and both of these values were higher (but not statistically different) than the FEV1 at the end of the run-in period $(2.19 \mathrm{~L})$. Analysed in individual patients, FEV1 was higher in three after the low-dose inhaler, whilst in three others FEV1 was higher after the standard-dose inhaler.

Mean PEF showed no difference between standardand low-dose treatment periods. Mean early morning PEF in run-in, standard-dose and low-dose periods was not significantly different. Morning PEF values were significantly lower than evening PEF values during all periods throughout the study $(\mathrm{p}<0.01)$. Analysis of individual PEF values showed that in six of the 20 patients $(30 \%)$ PEF was significantly different between treatment periods. In five patients PEF improved on the low-dose inhaler, two showing improvement both in morning and evening, two in morning only, and one in evening only. One patient only had a significant fall in evening PEF with the low-dose inhaler, but no significant fall in morning PEF.

Mean PEF variability similarly showed no differences between treatment periods or run-in, at $21 \pm 3 \%$ (run-in), $19 \pm 2 \%$ (standard-dose) and $18 \pm 2 \%$ (low-dose) (table 2). Eleven patients showed statistically significant differences in PEF variability between treatment periods; seven patients had more PEF variation on the low-dose inhaler, whilst four had less PEF variation.

\section{Symptom scores}

Mean symptom scores are shown in table 3. All patients were moderately symptomatic despite optimal inhaled glucocorticosteroid medication. No significant difference was observed between standard- and low-dose salbutamol in any mean symptom scores.

In 5 of the patients, symptom scores differed between standard- and low-dose salbutamol periods. Two woke more frequently at night with the low-dose, whereas one woke less often. Two had fewer symptoms during the day on the low dose, and one of these also had less early morning tightness. One patient noticed a significant improvement in daytime symptoms whilst on the standard dose compared with the low dose salbutamol.

Table 2. - Forced expiratory volume in one second $\left(F E V_{1}\right)$, peak expiratory flow rate (PEF) and variability, inhaler use and log provocative concentration of methacholine producing a $20 \%$ reduction in $\mathrm{FEV}_{1}\left(\mathrm{PC}_{20}\right)$ during study period $(\mathrm{n}=20)$

\begin{tabular}{lcccc}
\hline & Baseline & Run-in & $\begin{array}{c}\text { Low } \\
\text { dose }\end{array}$ & $\begin{array}{c}\text { Standard } \\
\text { dose }\end{array}$ \\
\hline FEV1 & 2.2 & 2.19 & 2.32 & 2.33 \\
& $(0.25)$ & $(0.23)$ & $(0.24)$ & $(0.22)$ \\
PEFR a.m. & - & 363 & 365 & 361 \\
& & $(27)$ & $(27)$ & $(29)$ \\
PEFR p.m. & - & 384 & 382 & 382 \\
& & $(30)$ & $(31)$ & $(32)$ \\
PEFR variability $\%$ & & 21 & 18 & 19 \\
& & $(2.8)$ & $(1.7)$ & $(2.2)$ \\
Inhaler usage $\mathrm{n}$ & & 6.8 & $8.3^{* *}$ & $7.5^{*}$ \\
& & $(0.8)$ & $(0.9)$ & $(0.8)$ \\
Log PC20 & -0.22 & -0.48 & -0.27 & -0.16 \\
& $(0.22)$ & $(0.21)$ & $(0.14)$ & $(0.19)$ \\
\hline
\end{tabular}

Values are presented as mean, and SEM in parenthesis. ${ }^{\dagger}$ : GSEM in brackets. *: $\mathrm{p}<0.05 ;{ }^{* *}: \mathrm{p}<0.001$ ANOVA compared to run in period. 
Table 3. - Symptom scores during study period $(n=20)$

\begin{tabular}{lccc}
\hline & Run-in & $\begin{array}{c}\text { Low } \\
\text { dose }\end{array}$ & $\begin{array}{c}\text { Standard } \\
\text { dose }\end{array}$ \\
\hline $\begin{array}{l}\text { Early morning } \\
\text { tightness }\end{array}$ & 0.96 & 0.98 & 1.0 \\
Asthma last & $(0.09)$ & $(0.1)$ & $(0.42)$ \\
night & 0.27 & 0.29 & 0.26 \\
Asthma during & $(0.09)$ & $(0.09)$ & $(0.09)$ \\
the day & 1.11 & 1.1 & 1.09 \\
\hline
\end{tabular}

For details of scoring system see text.

\section{Methacholine PC20}

PC20 to methacholine was measured only where FEV1 was $>65 \%$ of predicted, at baseline and at each subsequent study visit. Nine patients fulfilled this criteria consistently throughout the study. No significant difference was observed between baseline $\left(0.6 \pm 1.6 \mathrm{mg} \cdot \mathrm{mL}^{-1}\right)$; at the end of the run-in period $\left(0.33 \pm 1.6 \mathrm{mg} \cdot \mathrm{mL}^{-1}\right)$; after standard dose $\left(0.69 \pm 1.4 \mathrm{mg} \cdot \mathrm{mL}^{-1}\right)$ or after low dose $\left(0.53 \pm 1.5 \mathrm{mg} \cdot \mathrm{mL}^{-1}\right) \quad($ table 2$)$.

\section{Inhaler usage}

Subjects used their inhalers frequently, consistent with the aims of the study. Inhaler usage rose from $6.8 \pm 0.8$ actuations $\cdot$ day $^{-1}$ during the run-in period to $7.5 \pm 0.8$ actuations $\cdot$ day $^{-1}$ during the standard-dose period ( $\mathrm{p}=\mathrm{NS}$; table 2 ). Low-dose inhaler administration resulted in a statistically significant increase in inhaler actuations to $8.3 \pm$ 0.9 actuations $\cdot$ day $^{-1}(\mathrm{p}<0.04$, compared with standard treatment). Ten patients had a statistically significant difference in inhaler usage between standard- and lowdose treatment. In seven patients, inhaler usage went up with the low dose, and in three usage decreased. Mean dose of salbutamol consumed (calculated from number of inhaler actuations) was $5.36 \pm 0.56 \mathrm{~g} \cdot \mathrm{wk}^{-1}$ with standard-dose treatment and $2.89 \pm 0.34 \mathrm{~g} \cdot \mathrm{wk}^{-1}$ with lowdose treatment, representing a $46 \%$ reduction in dosage. Correlation between actual inhaler usage, as calculated by inhaler weights, and expected inhaler weight loss, as calculated from inhaler actuations recorded, was $75 \%$. Subjects underestimated inhaler usage both during standard-dose and low-dose treatment, with no significant difference in recording of actuations between these periods.

\section{Discussion}

Our study demonstrates that low dose salbutamol can provide adequate symptom relief in moderately severe asthma. Despite a $46 \%$ reduction in weekly salbutamol dosage, mean asthma symptom scores and PEF values remained unchanged overall in our patients, who were dependent on frequent salbutamol inhalations daily. Mean inhaler usage increased but did not double on low-dose salbutamol, consistent with a small increase in daytime symptoms, adequately treated by the low-dose inhaler.

Overall, the most striking feature was the lack of difference between low-dose and standard-dose treatment periods. Although PEF rose in three patients, and the changes were on average $30 \mathrm{~L} \cdot \mathrm{min}^{-1}$, similar to changes in other studies assessing anti-asthma agents [19], these changes were not always reflected by a change in symptom scores. Similarly, those patients in whom the PEF deteriorated did not show a worsening of asthma using other parameters of asthma control, probably reflecting a lack of sensitivity in the scoring system used.

FEV1 rose during the blinded standard salbutamol treatment period, probably due to a small placebo effect, and remained unchanged after the low-dose salbutamol treatment period. Low-dose inhaler usage, thus, had no detrimental effect on FEV1. We could not measure bronchial responsiveness in all our patients, (as 55\% of our subjects had $<65 \%$ predicted FEV1 on recruitment), but bronchial responsiveness was unchanged throughout the study, where measured. Bronchial reactivity did not increase during the low-dose treatment period, which might have suggested an increase in airway inflammation, or a rebound effect of $\beta_{2}$-agonist withdrawal.

We did not observe any overall improvement in asthma control. It is possible, however, that a longer treatment period is needed before any clinical improvement might result. In the study by SEARs et al. [2], although a more potent $\beta_{2}$-agonist was used and a larger number of patients studied, regular $\beta_{2}$-agonist treatment produced an effect on asthma exacerbation within 2 weeks. A reduction in bronchoprotection may also occur within this time [20]. Other studies, however, have shown no clinical deterioration using a short treatment period [21, 22].

This is the first time that a low-dose salbutamol MDI has been used for the control of asthma symptoms and to achieve $\beta_{2}$-agonist dose reduction. Despite several studies demonstrating the efficacy of low-dose inhalers in bronchodilation $[10,13]$, in protection against inhalational challenge [23] and in exercise-induced asthma [14], they have not been evaluated in clinical practice. Salbutamol can produce adequate bronchodilatation at less than $25 \mu \mathrm{g}[12,13]$, whilst low-dose fenoterol $(10 \mu \mathrm{g})$ produces similar bronchodilatation to $50 \mu \mathrm{g}$ and provides a 2.4 doubling dilution protection against histamine-induced bronchoconstriction [23, 24]. Maximal bronchodilator response can also be demonstrated to isoproteronol at doses as low as $20 \mu \mathrm{g}[13,25]$. Fenoterol is marketed at a dose approximately twice the potency of albuterol, and this relatively high dose may account for the increased relative risk of asthma morbidity and mortality, which has been reported with this drug [26]. It is recognized the $\beta_{2}$-agonists in higher dosage produce greater bronchodilatation [27]. The optimal degree of bronchodilation in asthma has, however, yet to be established.

Side-effects of $\beta_{2}$-agonists, in particular hypokalaemia and diastolic hypotension, increase dose-dependently with $\beta_{2}$-agonist treatment [28]. Substitution of a low-dose inhaler may reduce drug concentrations in the airway lumen, so that concentrations are insufficient for chronic receptor downregulation to develop, or to prevent a potentially negative $\beta_{2}$-agonist/glucocorticosteroid interaction [29]. It may, therefore, be important to use these drugs at the lowest possible dose which is of proven benefit. 
Our patients were deliberately selected for their high salbutamol usage despite high-dose inhaled glucocorticosteroid treatment. Our intention was to examine a population of asthmatic subjects who were symptomatic despite optimal antiinflammatory therapy, although stable, and who appeared to be dependent on $\beta_{2}$-agonist use. The conventional treatment options in this group include the addition of oral steroids, theophylline or a long-acting $\beta_{2}$-adrenoceptor agonist. An alternative may be to reduce the dose of $\beta_{2}$-agonist, a practice which is often difficult in patients who have used inhaled $\beta_{2}$-agonists over many years. SEARs [30] suggested education in symptom appreciation, together with clear peak flow guidelines. A slow decrease in dosage may also prove effective [31]. Our study suggests a low-dose salbutamol MDI may provide an acceptable alternative.

$\beta_{2}$-agonists have for years provided a relatively safe and effective remedy in asthma relief. Use of a lowdose inhaler may have a better safety profile and yet be as effective in day-to-day asthma symptom control. Our study has shown that such a strategy is possible in patients with moderately severe asthma in clinical practice. Further studies are needed to extend our findings and to establish the usefulness of low-dose $\beta_{2}$-agonists in asthma control over longer periods.

\begin{abstract}
Acknowledgements: The authors thank 3M Australia for provision of the inhalers and Astra Draco for financial support. MJP was supported by a Travelling Fellowship from Glaxo Australia. The authors also thank M. Worsdell for excellent technical assistance.
\end{abstract}

\section{References}

1. Barnes, PJ. New drugs for asthma. Eur Respir J 1993; 5: $1126-1136$.

2. Sears MR, Taylor DR, Print CG, et al. Regular inhaled beta-agonist treatment in bronchial asthma. Lancet 1990; 336: 1391-1396.

3. Taylor DR, Sears MR, Herbison GP, et al. Regular inhaled $\beta$-agonist in asthma: effects on exacerbations and lung function. Thorax 1993; 48: 134-138.

4. Spitzer W, Suissa S, Ernst P, et al. The use of betaagonists and the risk of death and near death from asthma. $N$ Engl J Med 1993: 326: 501-506.

5. Speizer FE, Doll R, Heaf P. Observations on recent increase in mortality from asthma. $\mathrm{Br}$ Med $J$ 1968; 1 : 335-339.

6. Inman W, Adelstein A. Rise and fall of asthma mortality in England and Wales in relation to use of pressurised aerosols. Lancet 1969; ii: 279-285.

7. Grainger J, Woodman K, Pearce NE, et al. Prescribed fenoterol and death from asthma in New Zealand, 1977-1981. Thorax 1991; 46: 105-111.

8. Van Metre T. Adverse effects of inhalation of excessive amounts of nebulized isoproterenol in status asthmaticus. J Allergy 1968: 101-1 13.

9. Reisman RE. Asthma induced by adrenergic aerosols. J Allergy 1970; 46: 162-177.

10. Choo-Kang YFJ, Simpson WT, Grant IWB. Controlled comparison of the bronchodilator effects of three $\beta$-adrenergic stimulant drugs administered by inhalation to subjects with asthma. Br Med J 1969; 2: 287-289.

11 Fraser PM, Speizer FE, Waters SD, Doll R, Mann NM.
The circumstances preceding death from asthma in young people in 1968 to 1969. Br J Dis Chest 1974; 65: 71-84.

12. Britton J, Hanley SP, Garrett HV, Hadfield JW, Tattersfield AE. Dose-related effects of salbutamol and ipratropium bromide on airway calibre and reactivity in subjects with asthma. Thorax 1988; 43: 300-305.

13. Barnes PJ, Pride NB. Dose-response curves to inhaled beta-adrenoceptor agonists in normal and asthmatic subjects. Br J Clin Pharmacol 1983; 15: 677-682.

14. Henriksen JM, Dahl R. Effects of inhaled budesonide alone and in combination with low-dose terbutaline in children with exercise-induced asthma. Am Rev Respir Dis 1983; 126: 993-997.

15. Haatela T, Nyberg A, Laurikain K, Silvasti N, Vidgren M. Dose of inhaled $\beta_{2}$-agonists in asthma. Lancet 1991; 337: 684.

16. American Thoracic Society. Standards for the diagnosis and care of patients with chronic obstructive pulmonary disease (COPD) and asthma. Am Rev Respir Dis 1987; 136: 225-244.

17. Cookson WO, Hopkin JM. Dominant inheritance of atopic immunoglobulin E responsiveness. Lancet 1988; i: $86-87$.

18. Nix A, Nichol GM, Barnes PJ, Chung KF. Effect of formoterol, a long-lasting $\beta_{2}$-adrenoceptor, against methacholine-induced bronchoconstriction. Br J Clin Pharmacol 1990; 29: 321-324.

19. Dahl R, Earnshaw JS, Palmer JBD. Salmeterol: a four week study of a long-acting beta-adrenoceptor agonist for the treatment of reversible airways disease. Eur Respir J 1991; 4: 1178-1184.

20. O'Connor BJ, Aikman SL, Barnes PJ. Tolerance to the nonbronchodilator effects of inhaled $\beta_{2}$-agonists in asthma. N Engl J Med 1992; 327: 1204-1208.

21. Chapman KR, Kesten S, Szalai JP. Regular vs as-needed salbutamol in asthma control. Lancet 1994; 343: 1379-1382.

22. Shepherd GL, Hetzel MR, Clark TJH. Regular versus symptomatic aerosol bronchodilator treatment of asthma. Br J Dis Chest 1981; 75: 215-217.

23. Magnussen H, Rabe KF. Low-dose fenoterol aerosol protects against histamine-induced bronchoconstriction in mild asthmatics: a dose-response study. Clin Exp Allergy 1992; 22: 690-693.

24. Lipworth BJ. The $\beta$-agonist controversy: fact or fiction? Clin Exp Allergy 1992; 22: 659-664.

25. Williams MH, Kane C. Dose-response of patients with asthma to inhaled isoproterenol. Am Rev Respir Dis 1975; 111: 321-326.

26. Grainger J, Woodman K, Pearce N et al. Prescribed fenoterol and death from asthma in New Zealand 1981-1987: a further case-control study. Thorax 1991; 46: 105-111.

27. Lipworth BJ, Clark RA, Dillon DP, Brown RA, McDevitt DG. Beta- adrenoceptor responses to high doses of inhaled salbutamol in patients with bronchial asthma. $\mathrm{Br}$ J Clin Pharmacol 1988; 26: 527-533.

28. Crane J, Burgess C, Beasley R. Cardiovascular and hypokalaemic effects of inhaled salbutamol, fenoterol and isoprenaline. Thorax 1989; 44: 136-140.

29. Peters MJ, Adcock IM, Brown CR, Barnes PJ (Abstract). $\beta$-agonist inhibition of steroid-receptor DNA binding activity in human lung. Am Rev Respir Dis 1993; 147 (4): A772.

30. Sears MR. Dose reduction of beta-agonists in asthma (Letter). Lancet 1991; 338: 1331-1332.

31. Peters MJ, Yates DH, Chung KF, Barnes PJ. $\beta_{2}$-agonist dose reduction: strategy and early results (Abstract). Thorax 1993; 48: 1066. 